\title{
3. Responding to Global Environmental Change
}

\author{
Mark Stafford Smith
}

Achieving change in individual and organisational behaviour to meet the challenges of global environmental change will be seen as a defining benchmark for our generation. Global environmental change challenges characteristically require inter-sectoral, multi-level responses within a fundamentally unpredictable complex systems framework. Here I focus on adaptation to climate change as an exemplar of these. Models of change that stress movement through phases of awareness, relevance, acceptance of agency and then action help to show that different motivators are required at different phases. Coupled with resilience theory and models of incremental and transformative change, they also help to identify what different modes of response should be targeted to different types of problem, and hence how engagement for change may be appropriately constructed. In the context of climate change adaptation, this leads to an enriched idea of adaptation pathways that meet many of the characteristics of global environmental changes.

The theme of this chapter is requisite complexity in responses to change - that is, 'one size does not fit all, but it is not helpful to have an indefinite number of sizes'. I explore this theme in the context of human change in response to global environmental change (e.g. Steffen et al. 2004). Responding to global environmental change in ways which are sufficiently but not excessively complex is a defining challenge for our generation, the first to really recognise that the human race is affecting sustainability at a global scale and the first, in science at least, to explore deeply the complex connectivities of social-ecological systems (Liu et al. 2007).

\section{The nature and significance of global environmental change}

Global environmental change refers to a suite of environmental impacts caused by human beings which are recognised as having effects that are global in scale. Indeed, the magnitude of these impacts has led to the proposal that we have entered a new geological epoch, the Anthropocene (Crutzen and Steffen 2003). An early recognised global environmental change was the hole in the ozone layer, where the emission of chlorofluorocarbon refrigerants mostly in the 
northern hemisphere was found to be dramatically affecting the ozone layer over Antarctica. Whilst climate change is today's iconic global environmental change, others include changes in the global water cycle, the global nitrogen and phosphorus cycles, ocean acidification, ecosystem loss and atmospheric pollution. These have been canvassed under the idea of nine planetary boundaries (Rockström et al. 2009) within which the world needs to stay to have confidence that the planet will continue to function in the relatively benign state that it has during the past 8,000 years. In this time, modern civilisation, agriculture, cities and technologies have developed. Of the nine boundaries, we have probably already transgressed three (Rockström et al. 2009). The concept of a 'safe operating space' with boundaries is a significant change from an engineering view of optimising our responses towards a specific desired future, since it does not seek to specify our collective actions within that space.

In general, these global environmental changes share some key attributes that interact with human decision-making. They all show a significant increase in their rates of change over the past 50 years - the so-called 'great acceleration' (see Figures 15 and 16 in Steffen 2010) - to the extent that the rates of human learning and decision-making processes risk being outstripped. They are all occurring at a spatial scale which seems far beyond the influence of individual humans. For most of them, it is certain that there is major change occurring on a decadal to centennial timeframe, but there is considerable uncertainty about where that change will end up and what impacts it will have. A large part of this uncertainty is a result of not knowing whether humanity will choose to respond to mitigate the changes.

This chapter takes climate change as an exemplar of the other global environmental changes. We now face the prospect of at least $2^{\circ} \mathrm{C}$ and up to $6^{\circ} \mathrm{C}$ of global warming by 2100 (IPCC 2007, Huntingford et al. 2012). Change is certain, but its magnitude depends greatly on human decisions. As with other global environmental changes, humanity must negotiate a balance between mitigating the magnitude of change and adapting to the changes which it is too late to mitigate. In some ways, adaptation to climate change has the same challenges as adapting to other drivers in society-planning for population increase, allowing for changing exchange rates, innovating into new technological markets. But whilst these contain uncertainty, only climate change exhibits so much certainty of major directional change over the long term, combined with uncertainty about the detailed trajectory.

This uncertainty presents a core challenge for climate adaptation, with many downstream implications. For example, issues of valuing the future compared with today; shifting risk management thinking from optimal solutions to robust decision-making; balancing short-term incremental change with harder, longer lead time, transformational change; placing everything in adaptive management 
and adaptive governance cycles rather than a one-off decision. A further key challenge is that adaptation responses need to be highly contextual; as a consequence, research tends to result in many case studies, but a limited ability to generalise these predictably for other contexts. We now turn to explore these issues.

\section{Models of human response}

A number of building blocks are emerging from the science of climate adaptation. To enable adaptation, people and organisations need to go through a sequence of steps (Figure 1) from initially understanding that there is an issue of climate change, to understanding their own vulnerability to climate change, to developing a sense of responsibility for responding to this vulnerability, to having a willingness to engage in adaptation planning, to acting on planning and implementation (Gardner et al. 2009). Recognising this sequence is important, because there are different drivers and barriers for moving from one step to the next, and people or organisations at different steps require different information to help them move onwards.

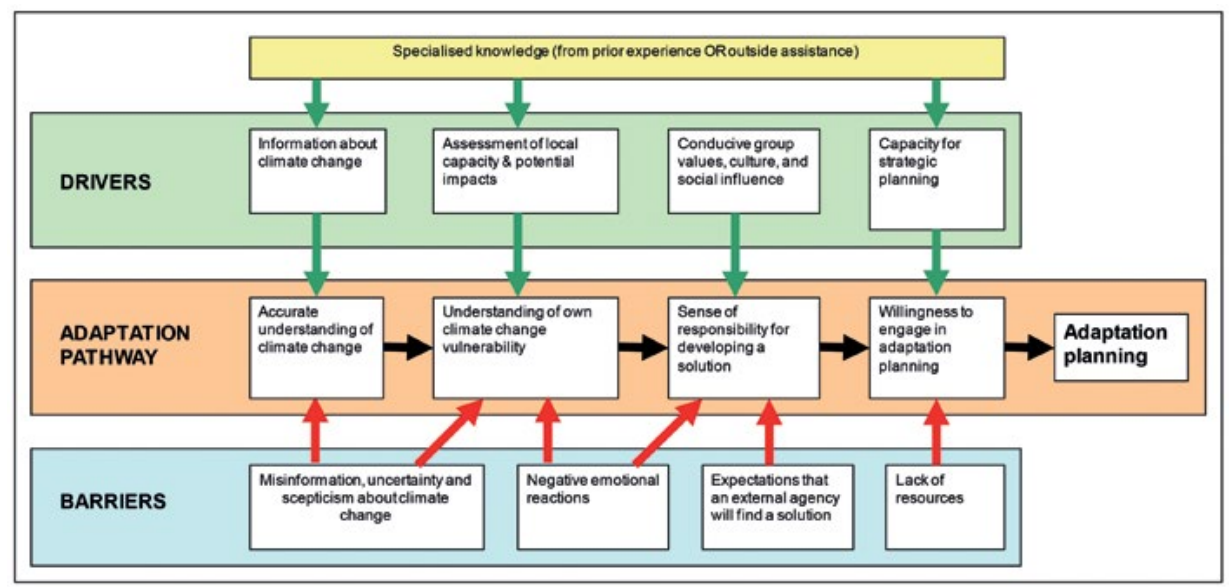

Figure 1 Steps people and organisations need to go through to adapt to global climate change, along with associated drivers and barriers.

Source: Modified from Figure 1 in Gardner et al. (2009).

Secondly, the characteristics of global environmental change problems noted above create specific difficulties for human cognition. Hamilton and Kasser (2009) note three categories of psychological strategies for responding to the prospect of severe climate change, ranging from various denial strategies, through a suite of maladaptive coping strategies, to genuinely adaptive coping strategies (see Table 1 in Stafford Smith et al. 2011). Understanding these is essential if 
people are to be facilitated through small steps on to the path of accepting the need to act; Crompton and Kasser (2009) suggest specific actions to encourage a move towards the adaptive strategies. However, there are also cognitive barriers to responding, particularly related to handling and misinterpreting long-term uncertainty (Weber 2006). Bazerman (2006) describes these as positive illusions (that a problem is not serious), egocentrism (interpreting events in a selfserving manner), over-discounting the future, privileging the status quo, and vividness (over-weighting personal experience). These mostly apply as much to organisational decision-making as they do to individuals, but are exacerbated by organisational silos and special interests that are legitimatised by corporate laws (e.g. the need to deliver short-term returns to shareholders). Collectively, these attributes provide hints towards facilitating change.

Thirdly, some change needs to be more than incremental (Kates et al. 2012, Park et al. 2012). Howden et al. (2010) explored the nature of incremental, transitional and transformational responses to climate change in agriculture, and noted that transformational change is more risky and expensive. It is also more cognitively challenging and has a longer lead-time (Stafford Smith et al. 2011). In reality, responses need to be seen as a continual cycle of incremental and transformational change (Park et al. 2012), adding further complexity to an overall adaptive cycle but converging with concepts such as triple loop learning (e.g. Chapin et al. 2009, Pahl-Wostl 2009).

Fourthly, there is a vast literature on organisational innovation, adoption and change (e.g. Greenhalgh et al. 2004, Pentland et al. 2011, Berkhout 2012). This is valuable in identifying many factors which may play a role in different contexts, such as leadership, structure, trigger events, resources and timing, but the literature struggles to get beyond shopping lists of such potential influences to be predictive in different contexts. Some of our own recent work has explored the issue of mainstreaming in the climate adaptation domain. In conversations with champions for adaptation in various organisations, for example, we have found that where the locus of influence for acting on climate change resides in the organisation's executive function, it is far easier to trigger implementation than when the locus is elsewhere. In the former case, interview responses focus on the nature of business-as-usual in different parts of the organisation. In the latter, conversations concentrate on the attributes of the champion, such as their ability to network with other parts of the organisation and in various ways achieve implementation despite (rather than because of) the structure. 


\section{Responses in climate adaptation}

How should we respond to these issues in adapting to climate change, as an example of global environmental changes? First, let us distinguish three functionally different response roles. There is a commonplace narrative that asserts 'all adaptation is local', with the corollary that the role of government is simply to set the context within which local communities or businesses make decisions. In reality, adaptation decisions can be made at any scale, including in government, and so can 'policy' decisions that set the context for other decision-makers (Palutikof et al. 2013), but the two roles-in implementation and context-setting - are functionally useful to distinguish. The third role I wish to consider a little is that of researchers. Here I will abbreviate these functional roles as adaptation action, policy and research respectively.

Next, it is notable that climate change, as with many other environmental changes, has largely been approached through a problem-oriented framing. For good reason, climate scientists spent many years trying to show that there really was a problem which was worth tackling, and the Intergovernmental Panel on Climate Change process and report structure still emphasise the potential for climate change first, and its implications in terms of impacts and possible mitigation second. One result of this is the strong primacy of a hazard approach to impacts and vulnerability (Wolf 2012)-exposure and sensitivity defining impact, and impact and adaptive capacity defining residual vulnerability (Figure 2). Aside from a variety of technical and conceptual faults with this framing, it focuses attention on the problem of vulnerability rather than on potential response options; it also tends to give the impression that all actions will eventually be affected by climate change (potentially true), leading to paralysis or denial. Another result is that uncertainty in the climate projections is perceived to 'cascade' through impacts and vulnerability, with uncertainty increasing at each step to further challenge any ability to make decisions (Stainforth et al. 2007) (Figure 3).

These effects immediately play into undermining human responses. There is an increasing understanding that continuing to batter people with the problem rather than with solutions simply turns them off, particularly when that problem seems a long way into the future. And, whilst there are genuinely important uncertainties, overemphasising these again sparks all the cognitive challenges mentioned above. In fact, there has long been an alternative but muffled framing which is decision-centred rather than problem-oriented. This traces its antecedents to the adaptive management literature (e.g. Walters 1986, Walters and Holling 1990, Chapin et al. 2009), and has been readily available in the context of adapting to climate change for at least a decade through the efforts of UKCIP, formerly the UK Climate Impacts Programme (e.g. Willows and Connell 2003) (Figure 4). As decision-makers have increasingly turned to wanting to act on 
adaptation rather than just worry about whether climate change is real, this line of thinking has come more to the fore (Stafford Smith et al. 2011, Haasnoot et al. 2013), but is still not widely embedded in the thinking of adaptation policy, so that those seeking to plan for adaptation action often get stuck at the point of considering distant and uncertain impacts and vulnerabilities. Additionally, much research continues to emphasise the problem-oriented framing, due to the distance of most researchers from decision-makers, and a strongly entrenched dominance of climate science (Sarewitz and Pielke 2007).

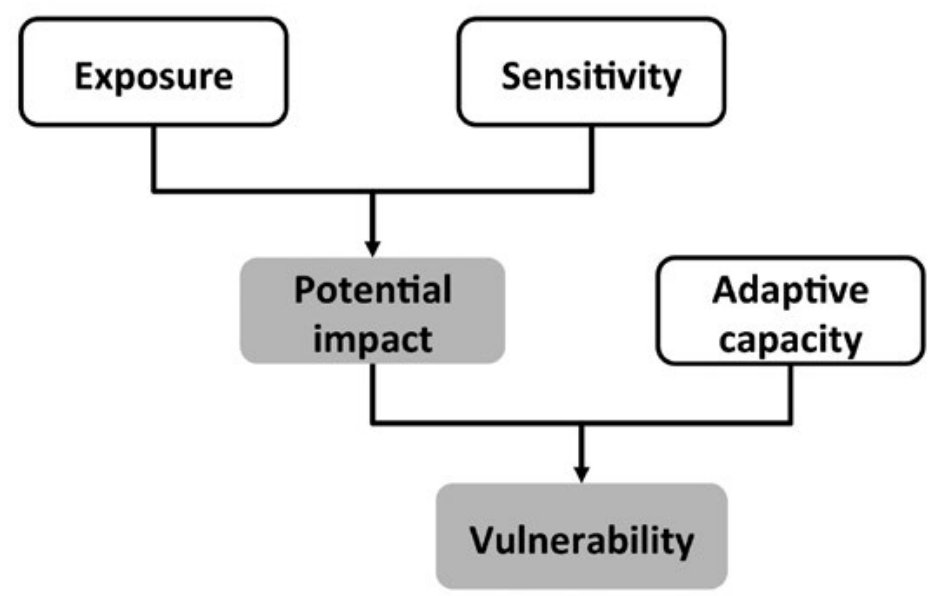

Figure 2 A common framing of impact and vulnerability.

This has technical and conceptual faults and focuses attention on problems rather than potential response options.

Source: Modified from Allen Consulting (2005).

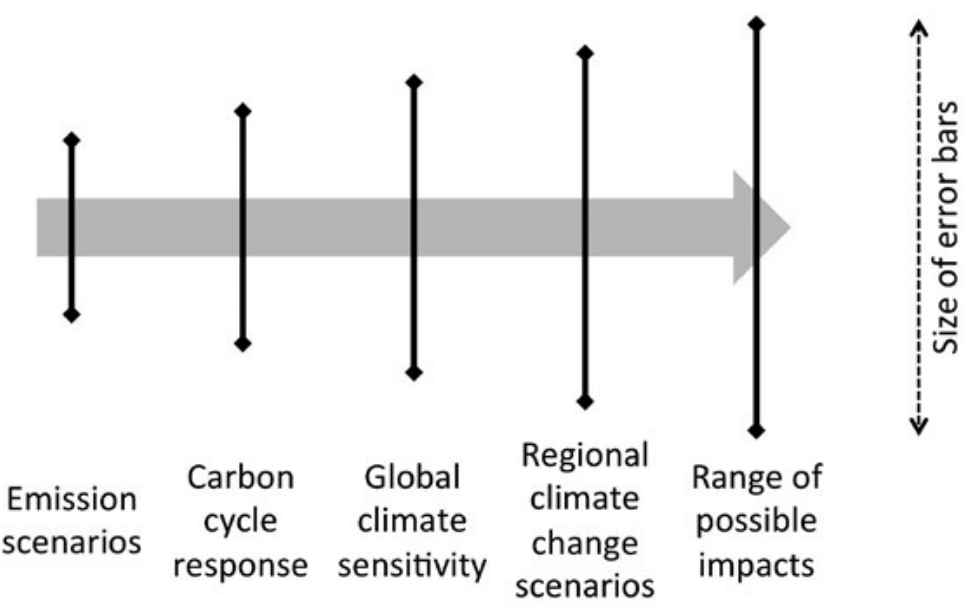

Figure 3 A perceived 'cascade' through impacts and vulnerability, with uncertainty increasing at each step.

This can undermine human ability to respond, and does not necessarily represent the relative importance of the uncertainties in an actual decision. 


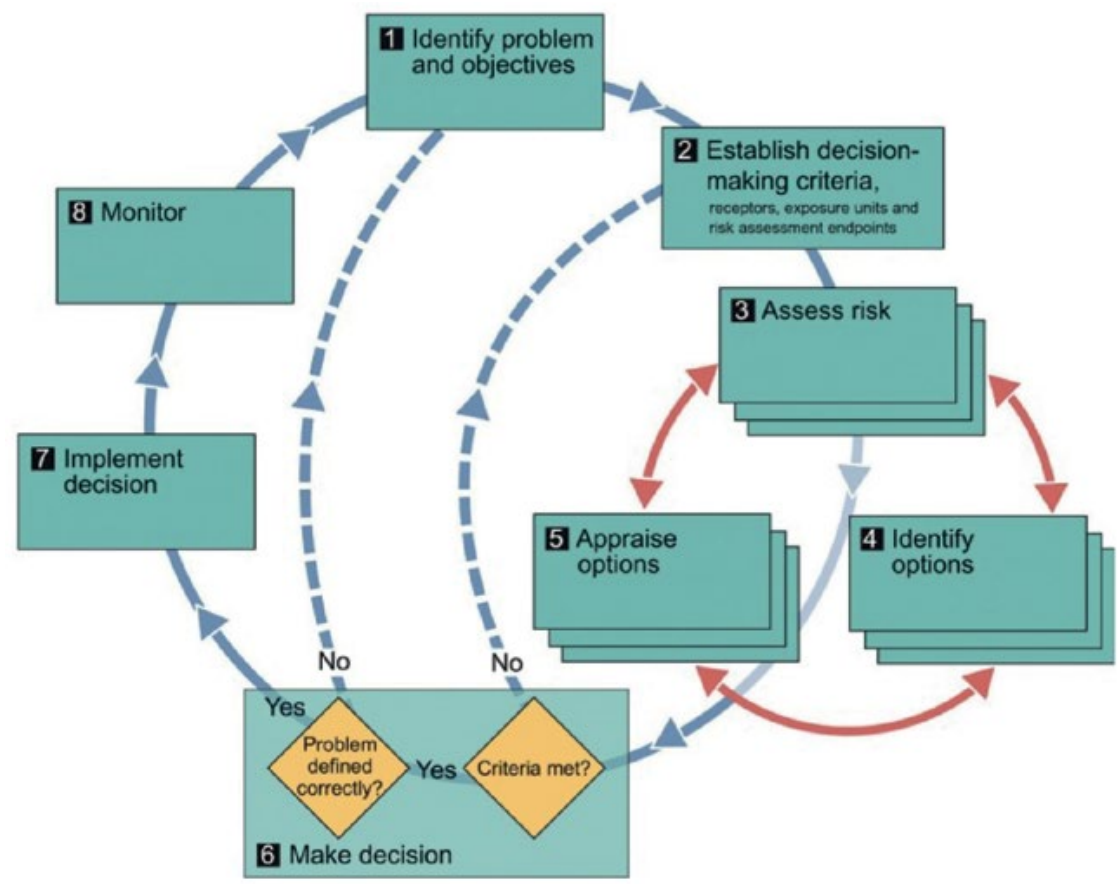

\section{Figure 4 The UK Climate Impacts Programme (UKCIP) decision-centred model, which promotes more productive responses.}

Source: Reproduced from Willows and Connell (2003).

A decision-centred framing resolves several problems. It asks, 'What decisions do either policy or action decision-makers face now?', and then, 'Which of these may be affected by future climate change?' Since most decisions have a lifetime that is quite short, this immediately narrows down the otherwise overwhelming suite of decisions that might be affected by climate change to a much smaller number (Stafford Smith et al. 2011). It also enables an assessment of the particular element of climate change that may affect each individual decision, and then a characterisation of the nature of uncertainty in that element, rather than being clouded by a pervasive sense of overall uncertainty. Indeed, when put in the context of other sources of uncertainty related to the decision, it may turn out that the climate uncertainty is not actually important - far from cascading, at times the implications of climate uncertainty may instead be attenuated. Where uncertainty remains, various ways of mitigating decision risk can be drawn upon (Hallegatte 2009) and the set of choices can be dynamically redefined through a series of potential adaptation pathways (Figure 5) out into the future wherein not all problems have to be solved at once (Haasnoot et al. 2013, Wise et al. 2014). Not all decisions can be so broken up, but most can: essentially decision-centred framing is replacing single shot, long-range artillery with its challenging need to get everything right in one go despite the risk of unexpected 
winds, with a game of golf, zigzagging adaptively up the fairway, ${ }^{1}$ avoiding maladaptation and undesirable path contingency. Together these features facilitate adaptation action by making the process more relevant. They also highlight the need for adaptation policy decision-makers not to overemphasise vulnerability assessments. For researchers, a decision-driven conceptualisation would also better focus much adaptation research.

Reframing the issue not only helps reduce the cognitive gap between the information being provided and the decision-making environment of those actors who may need to respond, but also focuses attention on the context in which the decision is occurring. As reviewed by Wise et al. (2014), Voß et al. (2007) identify a typology of contexts along a gradient of increasing complexity based on levels of uncertainty in knowledge, goals and distributed power, which can guide the appropriate choice of methodologies (e.g. Randall et al. 2012). Where system functioning is well understood and future risks well characterised, goals or values are clear and there is a central decision-maker, problems are well suited to the rationalist reductionist approach to decision-making, and tools such as cost-benefit analysis are suitable. In relatively closed systems with a central locus of power and unambiguous goals (e.g. high reliability urban water supply systems), the 'knowledge problem' can be tackled through capability building, learning approaches and tools for decision-making under uncertainty (e.g. Dessai and van de Sluijs 2007, Hallegatte 2009). However, many complex systems contexts have a high degree of uncertainty in knowledge, as well as distributed power and ambivalent goals; in these there are no agreed values, and even the institutions intended to help resolve them may be contested or not exist, as can be the case in coastal responses to sea-level rise in Australia (Gorddard et al. 2012). In such circumstances, engagement processes, perhaps a deliberative democracy approach, and certainly an iterative approach to framing decision process are required, as is urged in strategic adaptive management (cf. Roux and Foxcroft 2011, Randall et al. 2012). It is worth noting, however, that these more complex approaches are expensive in time and energy, so it is essential to identify cases where simpler, cheaper approaches are sufficient, as opposed to cases where these are likely to fail so that more complex approaches are justified.

1 I am indebted to Paul Griffiths for this insightful metaphor from the sporting tradition of the philosophy of science. 


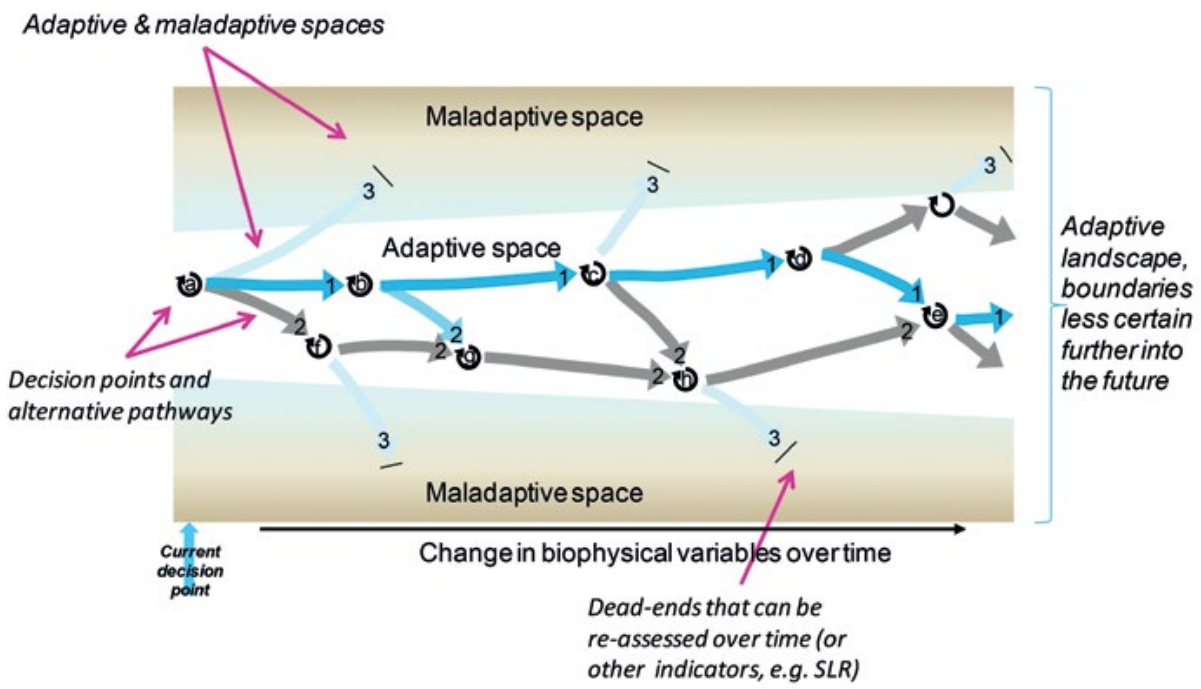

\section{Figure 5 Conceptualising dynamic adaptation pathways.}

A decision-maker at point (a) can envision various pathways of action across a landscape that is moreor-less adaptive (hitting the ball down the fairway and avoiding the maladaptive rough, in the golfing analogy). At point (a), some decisions are likely to be maladaptive and should be avoided; there remain multiple possible pathways, of which one seems best at the time of initial decision-making. Following the analysis, this first step can therefore be taken with confidence, knowing that re-appraisal at point (b) may mean choosing the shift to path (g)-(e) instead. It is important to explicitly define the decision's points, which may be points in time, or other triggers such as sea level rise.

Source: Adapted from Wise et al. (2014).

A decision-centred approach also emphasises the nature of the decision-maker themselves. Not only is this important in terms of the phases of readiness (Gardner et al. 2009) described earlier, but also in the ease of mainstreaming the topic even once the decision-maker is ready to consider it. If the implementation is close to current business-as-usual, it seems that the action can (and should for efficiency's sake) be readily mainstreamed; but where there is a major mismatch between the needed response and business-as-usual practices, then premature mainstreaming is likely to fail. This outcome is thus a conjoint property of both the needed response (itself related to the nature of the problem) and the characteristics of the decision-making individual or organisation - essentially a question of whether these aspects are 'in balance' or not. Even an organisation with very short-term planning horizons and low capacity may be able to cope with more incremental, shorter term, less contested responses, just as even a far-seeing, high capacity organisation may be challenged by very long-term transformative issues. 
The concept of dynamic adaptation pathways can help to bring all these elements together and provide a structured approach of requisite complexity to complex decision-making that may otherwise dissolve into oversimplification or complexity-driven paralysis (Haasnoot et al. 2013, Wise et al. 2014).

\section{Conclusions}

Thus some simple guidelines can emerge for dealing with complex global environmental changes, which enable actors to structure their approaches in ways which are cognitively achievable and appropriate to their roles in decisionmaking. The choice of responses must take account of the nature of the problem, of the actors and of their normal modes of operating; focusing on any single dimension is bound to be inadequate. Lenses such as power and equity can be taken into these attributes. People, communities and institutions will be at different stages of acceptance and response and need different information and tools to assist them on to the next stage. The specific problems they face in their own context will require different levels of responses, from simple amendments to business-as-usual operations to deeply challenging transformative changes to ways of thinking, and different tools and approaches are again required for these. And different actors in society need to recognise and play their different roles in supporting the responses. These statements seem to be very obvious and widely documented in their parts; and indeed applicable in triggering adaptive responses to changes with similar complex characteristics that inhibit decisionmaking well outside the arena of global environmental change. Yet they have not been salient in the way in which the climate change issue has been progressed over the past few decades, perhaps partly because our collective understanding has not seen how these approaches apply in the context of global complex systems problems. It is time we changed this.

\section{References}

Allen Consulting (2005) Climate change risk and vulnerability. Final report to the Australian Greenhouse Office by the Allen Consulting Group. Australian Greenhouse Office, Department of the Environment and Heritage, Canberra.

Bazerman, MH (2006) Climate change as a predictable surprise. Climate Change 77: 179-93.

Berkhout, F (2012) Adaptation to climate change by organizations. Wiley Interdisciplinary Reviews: Climate Change 3: 91-106. 
Chapin, FS III, Kofinas, GP and Folke, C (eds) (2009) Principles of ecosystem stewardship: resilience-based natural resource management in a changing world. Springer-Verlag, New York.

Crompton, $\mathrm{T}$ and Kasser, $\mathrm{T}$ (2009) Meeting environmental challenges: the role of human identity. WWF, Godalming UK.

Crutzen, PJ and Steffen, W (2003) How long have we been in the Anthropocene era? Climatic Change 61: 251-7.

Dessai, S and van de Sluijs, J (2007) Uncertainty and climate change adaptation - a scoping study (report for the Netherlands Environmental Assessment Agency). Copernicus Institute for Sustainable Development and Innovation, Utrecht University, Utrecht.

Gardner, J, Dowd, A-M, Mason, C and Ashworth, P (2009) A framework for stakeholder engagement on climate adaptation. CSIRO Climate Adaptation Flagship working paper no 3. CSIRO Climate Adaptation Flagship, Canberra.

Gorddard, R, Wise, R, Alexander, K, Langston, A, Leitch, A, Dunlop, M, Ryan, A and Langridge, J (2012) Striking the balance: coastal development and ecosystem values (CSIRO Climate Adaptation Flagship project report). Commonwealth of Australia, Canberra.

Greenhalgh, T, Robert, G, Macfarlane, F, Bate, P and Kyriakidou, O (2004) Diffusion of innovations in service organizations: systematic review and recommendations. Milbank Quarterly 82: 581-629.

Haasnoot, M, Kwakkel, JH, Walker, Warren E and ter Maat, J (2013) Dynamic adaptive policy pathways: a method for crafting robust decisions for a deeply uncertain world. Global Environmental Change 23: 485-98.

Hallegatte, S (2009) Strategies to adapt to an uncertain climate change. Global Environmental Change: Human and Policy Dimensions 19: 240-7.

Hamilton, C and Kasser, T (2009) Psychological adaptation to the threats and stresses of a four degree world. 'Four Degrees and Beyond' conference. Environmental Change Institute, Oxford University, Oxford.

Howden, SM, Crimp, SJ and Nelson, RN (2010) Australian agriculture in a climate of change. In Jubb, I, Holper, P and Cai, W (eds) Managing Climate Change: papers from the GREENHOUSE 2009 Conference. CSIRO Publishing, Melbourne: 101-11. 
Huntingford, C, Lowe, JA, Gohar, LK, Bowerman, NHA, Allen, MR, Raper, SCB and Smith, SM (2012) The link between a global $2{ }^{\circ} \mathrm{C}$ warming threshold and emissions in years 2020, 2050 and beyond. Environmental Research Letters 7, www.ceh.ac.uk/staffwebpages/documents/huntingford_et_al_12.pdf.

Intergovernmental Panel on Climate Change (IPCC) (2007) Summary for Policymakers. In Solomon, S, Qin, D, Manning, M, Chen, Z, Marquis, M, Averyt, KB, Tignor, $\mathrm{M}$ and Miller, HL (eds) Climate Change 2007: the physical science basis. Contribution of Working Group I to the Fourth Assessment Report of the Intergovernmental Panel on Climate Change. Cambridge University Press, Cambridge UK.

Kates, RW, Travis, WR and Wilbanks, TJ (2012) Transformational adaptation when incremental adaptations to climate change are insufficient. Proceedings of the National Academy of Sciences 109: 7156-61.

Liu, JG, Dietz, T, Carpenter, SR, Alberti, M, Folke, C, Moran, E, Pell, AM, Deadman, P, Kratz, T, Lubchenco, J, Ostram, E, Ouyang, Z, Provencher, W, Redman, CL, Schneider, SH and Taylor, WW (2007) Complexity of coupled human and natural systems. Science 317: 1513-16.

Pahl-Wostl, C (2009) A conceptual framework for analysing adaptive capacity and multi-level learning processes in resource governance regimes. Global Environmental Change: Human and Policy Dimensions 19: 354-65.

Palutikof, J, Parry, M, Stafford Smith, M, Ash, AJ, Boulter, SL and Waschka, M (2013) The past, present and future of adaptation: setting the context and naming the challenges. In Palutikof, J, Boulter, SL, Ash, AJ, Stafford Smith, M, Parry, M, Waschka, M and Guitart, D (eds) Climate adaptation futures. Wiley Publishing, Oxford: 3-29.

Park, SE, Marshall, NA, Jakku, E, Dowd, AM, Howden, SM, Mendham, E and Fleming, A (2012) Informing adaptation responses to climate change through theories of transformation. Global Environmental Change 22: 115-26.

Parry, ML, Canziani, OF, Palutikof, JP, van der Linden, PJ and Hanson, CE (eds) (2007) Climate Change 2007: impacts, adaptation and vulnerability. Contribution of Working Group II to the Fourth Assessment Report of the Intergovernmental Panel on Climate Change. Cambridge University Press, Cambridge UK.

Pentland, D, Forsyth, K, Maciver, D, Walsh, M, Murray, R, Irvine, L and Sikora, S (2011) Key characteristics of knowledge transfer and exchange in healthcare: integrative literature review. Journal of Advanced Nursing 67: 1408-25. 
Randall, A, Capon, T, Sanderson, T, Merrett, D and Hertzler, G (2012) Choosing a decision-making framework to manage uncertainty in climate adaptation decision-making: a practitioner's handbook. National Climate Change Adaptation Research Facility / University of Sydney, Sydney.

Rockström, J, Steffen, W, Noone, K, Persson, Å, Chapin, FS III, Lambin, EF, Lenton, TM, Scheffer, M, Folke, C, Schellnhuber, HJ, Nykvist, B, de Wit, CA, Hughes, T, van der Leeuw, S, Rodhe, H, Sörlin, S, Snyder, PK, Costanza, R, Svedin, U, Falkenmark, M, Karlberg, L, Corell, RW, Fabry, VJ, Hansen, J, Walker, B, Liverman, D, Richardson, K, Crutzen, P and Foley, JA (2009) A safe operating space for humanity. Nature 461: 472-5.

Roux, DJ and Foxcroft, LC (2011) The development and application of strategic adaptive management within South African National Parks. Koedoe 53, article 1049: 5 pp, www.koedoe.co.za/index.php/koedoe/article /view/1049.

Sarewitz, D and Pielke, RA (2007) The neglected heart of science policy: reconciling supply of and demand for science. Environmental Science \& Policy 10: 5-16.

Stafford Smith, M, Horrocks, L, Harvey, A and Hamilton, C (2011) Rethinking adaptation for a $4^{\circ} \mathrm{C}$ World. Philosophical Transactions of the Royal Society A-Mathematical, Physical and Engineering Sciences 369: 196-216.

Stainforth, DA, Downing, TE, Washington, R, Lopez, A and New, M (2007) Issues in the interpretation of climate model ensembles to inform decisions. Philosophical Transactions of the Royal Society A-Mathematical, Physical and Engineering Sciences 365: 2163-77.

Steffen, W (2010) Observed trends in Earth System behavior. Wiley Interdisciplinary Reviews: Climate Change 1: 428-49.

Steffen, W, Sanderson, RA, Tyson, PD, Jäger, J, Matson, PA, Moore B III, Oldfield, F, Richardson, K, Schellnhuber, HJ, Turner, BL and Wasson, RJ (2004) Global change and the Earth system: a planet under pressure. SpringerVerlag, Heidelberg.

Voß, J-P, Newig, J, Kastens, B, Monstadt, J and Nölting, B (2007) Steering for sustainable development: a typology of problems and strategies with respect to ambivalence, uncertainty and distributed power. Journal of Environmental Policy and Planning 9: 193-212.

Walters, CJ (1986) Adaptive management of renewable resources. Macmillan Publishing Co., New York. 
Change!

Walters, CJ and Holling, CS (1990) Large-scale management experiments and learning by doing. Ecology 71: 2060-8.

Weber, EU (2006) Experience-based and description-based perceptions of longterm risk: why global warming does not scare us (yet). Climatic Change 77: 103-20.

Willows, R and Connell, R, eds (2003) Climate adaptation: risk, uncertainty and decision-making. UKCIP (United Kingdom Climate Impacts Programme), Oxford.

Wise, RM, Fazey, I, Stafford Smith, M, Park, SE, Eakine, HC, Archer Van Garderen, ERM, Campbell, B and Wolf, S (2014) Reconceptualising adaptation to climate change as part of pathways of change and response. Global Environmental Change, 28: 325-36.

Wolf, S (2012) Vulnerability and risk: comparing assessment approaches. Natural Hazards 61: 1099-1113. 
This text is taken from Change! Combining Analytic Approaches with Street Wisdom, edited by Gabriele Bammer, published 2015 by ANU Press, The Australian National University, Canberra, Australia. 